\title{
Comparison of Nebivolol and Bisoprolol for Cardiovascular Mortality in Hypertensive Patients
}

\author{
Ratan Kumar $^{1}$, Kheraj Mal ${ }^{2}$, Jamila Begum ${ }^{3}$, Faizan Shaukat ${ }^{4}$ \\ 1. Cardiology, Khairpur Medical College, Nawabshah, PAK 2. Cardiology, National Institute of Cardiovascular Diseases, \\ Sukkur, PAK 3. Internal Medicine, Dow University of Health Sciences, Karachi, PAK 4. Internal Medicine, Jinnah Post \\ Graduate Medical Center, Karachi, PAK
}

Corresponding author: Faizan Shaukat, faizan.shaukat89@gmail.com

\section{Abstract}

\section{Introduction}

Beta-blockers again are now considered as first-line therapy for various cardiovascular diseases. In this study, we compare the cardiovascular event between two beta-blocker, i.e. Nebivolol and Bisoprolol.

\section{Materials and Methods}

It is a two-arm open-label randomized prospective study that was conducted from $1^{\text {st }} J a n 2016$ to $30^{\text {th }}$ July 2019 in tertiary care hospital, Nawabshah. One thousand and fifty-six $(n=1056)$ hypertensive patients were enrolled after informed consent, which were randomized into two equal groups. Patients were followed up for one year.

\section{Results}

Comparison between Nebivolol and Bisoprolol showed that all-cause mortality (9.8\% vs $11.48 \%$ ), cardiovascular mortality (5.4\% vs 7.0\%), all-cause hospitalization (14.4\% vs $16.3 \%)$, and cardiovascular hospitalization ( $9.8 \%$ vs $12.09 \%$ ) was numerically lower in nebivolol but the difference was not statistically significant.

\section{Conclusion}

Further large scale multicentric trials with a longer follow up period are needed to compare various betablockers for cardiovascular event.

Categories: Cardiology, Internal Medicine

Keywords: cardiology, bisoprolol, nebivolol

Received 12/10/2019

Review began 12/13/2019 Review ended 12/17/2019 Published 12/23/2019

๑) Copyright 2019

Kumar et al. This is an open access article distributed under the terms of the Creative Commons Attribution License CC-BY 3.0., which permits unrestricted use, distribution, and reproduction in any medium, provided the original author and source are credited.

\section{Introduction}

Agents that block the adrenergic $\beta$-receptors, beta-blockers, have been a cornerstone for the treatment and management of cardiovascular disease (CVD) for more than a decade. Increase survival rate and expectancy of patients with CVD due to the development of primary prevention and early-detection strategies along with the development of new and effective therapeutic agents has increased the prevalence of cardiovascular disease [1]. In 2013, European Society of Cardiology (ESC) moved beta-blocker to second-line therapy for the treatment of essential hypertension based on various meta-analysis conducted on betablockers such as atenolol and propranolol [2-3]. ESC, in 2018, issued its guideline, which suggested betablocker as the first line of therapy for indications such as heart failure, hypertension with angina, hypertension with myocardial infarction, coronary artery disease [4]. This change in attitude towards the use of beta-blocker is mainly due to the introduction of a new generation of beta-blockers such as Nebivolol. Various data on Nebivolol have shown that it has increasing favorable effects on central blood pressure, stiffness of the aorta, and endothelial dysfunction. There is no risk of new-onset diabetes, and a more favorable side effect profile compared to conventional beta-blockers [4]. Bisoprolol, carvedilol, and nebivolol have shown to improve outcomes in RCTs in heart failure [5]. Despite being in use in Pakistan for decades, there is limited data available regarding cardiovascular protection offered by beta-blockers. In this study, we will compare the two most commonly used beta-blockers (Nebivolol and Bisoprolol) for the cardiovascular outcome.

\section{Materials And Methods}

This two-arm open-label randomized prospective study was conducted from 1st Jan 2016 to 30th July 2019 in tertiary care hospital, Nawabshah. One thousand and fifty-six $(n=1056)$ hypertensive patients were enrolled after informed consent, which were randomized by a 1:1 ratio using an online software research randomizer. Group A was given standard hypertensive therapy (angiotensin-converting enzyme inhibitors, angiotensin 


\section{Cureus}

receptor blockers, calcium channel blocker or diuretics) and Nebivolol. Group B was given standard hypertensive therapy and Bisoprolol.

Patient's characteristics such as age, gender, history of smoking, duration of hypertension, family history were noted in the self-structured questionnaire. Their standing blood pressure was also recorded. Patients were followed for a minimum of one year for the development of any cardiovascular event. Patients with less than one year of follow up were counted as lost to follow up.

Statistical analysis was done using SPSS v. 22.0 (IBM Corporation, Armonk, New York, United States). Continuous variables including age, blood pressure (BP), and duration of hypertension were analyzed via descriptive statistics and were presented as mean and standard deviation (SD) while categorical variables, including gender, smoking history, and cardiovascular outcomes were presented by percentages and frequencies.

\section{Results}

One thousand and fifty-eight (1058) participants were enrolled and randomized into two equal groups; one with Nebivolol and one with Bisoprolol. The characteristics were comparable between the two groups except for BMI. Lost to follow up were 29 and 33 participants for Nebivolol and Bisoprolol, respectively (Table 1).

\begin{tabular}{|c|c|c|c|}
\hline Cnaracteristics & Patients with Nebivolol $(n=529)$ & Patients with Bisoprolol $(n=529)$ & P-value \\
\hline Age & $54 \pm 19$ & $55 \pm 19$ & 0.58 \\
\hline Male/Female & $301 / 228$ & $289 / 240$ & 0.55 \\
\hline Smoking & 152 & 149 & 0.8 \\
\hline Diabetes & 76 & 71 & 0.6 \\
\hline BMI & $24.56 \pm 5.19$ & $23.17 \pm 6.09$ & 0.001 \\
\hline Previous history of AMI & 17 & 21 & 0.58 \\
\hline Family history of AMI & 28 & 26 & 0.77 \\
\hline Lost to follow up & 29 & 33 & 0.6 \\
\hline
\end{tabular}

\section{TABLE 1: Characteristics of Participants}

AMI: Acute myocardial infarction.

Primary outcomes were noted one year after follow up. There were numerically less events in the Nebivolol group compared to Bisoprolol; however, the result was not statistically significant (Table 2).

\begin{tabular}{|c|c|c|c|c|}
\hline Primary Outcome & Nebivolol $(n=500)$ & Bisoprolol (n=496) & HR & P-Value \\
\hline All-cause mortality & $49(9.8 \%)$ & $57(11.49 \%)$ & 0.77 (0.53 to 1.11$)$ & 0.16 \\
\hline CV mortality & 27 (5.4\%) & $35(7.0 \%)$ & 0.76 (0.47 to 1.24$)$ & 0.28 \\
\hline All-cause hospitalization & $72(14.4 \%)$ & $81(16.3 \%)$ & 0.88 (0.65 to 1.18$)$ & 0.39 \\
\hline CV hospitalization & 49 (9.8\%) & $60(12.09 \%)$ & 0.80 (0.56 to 1.15$)$ & 0.23 \\
\hline
\end{tabular}

\section{TABLE 2: Primary Outcome}

CV: Cardiovascular

\section{Discussion}

Nebivolol has a unique mechanism of action that defers from other beta-blockers. In addition to cardioselectivity mediated via $\beta 1$ receptor blockade, Nebivolol also works as a B3 agonist, which induces nitric oxide-mediated vasodilation by stimulating endothelial nitric oxide synthase [6]. Bisoprolol work by blocking the beta-1-receptor [7]. In this study, we compared the cardiovascular outcomes of patients on nebivolol and Bisoprolol. Nebivolol reduced the incidence of cardiovascular events numerically more than 
Our result echoes the result of Nebivolol, Bisoprolol Multicenter Study (NEBIS), which concluded there is no difference in blood pressure control between nebivolol and Bisoprolol [8]. CARNEBI (Multiparametric comparison of CARvedilol, vs. Nebivolol, vs. Bisoprolol in moderate heart failure) showed improvement in exercise performance $(\mathrm{p}<0.0001)$ with nebivolol and Bisoprolol [9].

Individual trials of both Nebivolol and Bisoprolol have shown that they reduce cardiovascular events. Study of Effects of Nebivolol Intervention on Outcomes and Rehospitalization in Seniors with Heart Failure (SENIORS) showed that nebivolol significantly reduces all-cause mortality or cardiovascular hospitalization compared to placebo $(95 \%$ CI): 0.86 (0.74-0.99); $\mathrm{p}=0.039[10]$. The cardiac insufficiency bisoprolol study (CIBIS-II) showed significant mortality advantages over placebo. All-cause mortality was significantly lower with bisoprolol than on placebo $(156[11.8 \%]$ vs. $228[17.3 \%]$ deaths with a hazard ratio of 0.66 [11].

Better cardiovascular protection by Nebivolol can be explained because of its unique mechanism of action and super selectivity. Nebivolol has 321-fold higher affinity for human cardiac beta1-receptors versus beta2-receptors making it more selective for beta1-receptors than any other agent in its class [12]. Nebivolol is 3.5 times more beta-1-adrenoreceptor selective than bisoprolol [13]. Nebivolol because its action on the B3 receptor releases nitric oxide, which may reverse endothelial dysfunction and hence speculated to reverse atherosclerosis [14]. Nitric oxide acts as an endogenous inhibitor of platelet aggregation in the platelets. Hence, nebivolol inhibits platelet aggregation triggered by adenosine diphosphate and collagen [15]. Nebivolol also inhibits the proliferation of human coronary endothelial cells, aortic smooth muscle cells, and smooth muscle cells via nitric oxide delivery [16].

To the best of its knowledge, it is the first study that has compared the cardiac outcome of patients on Nebivolol and Bisoprolol in Pakistan. However, the study has its own limitation. First, there was a statistical difference in body mass index (BMI) between the two groups. Secondly, the follow-up period was only one year. Hence, long-term results were not noted. There were other confounding factors such as cholesterol level and lifestyle, which was not taken to account.

\section{Conclusions}

In this study, overall mortality, over-all hospitalization, CV mortality, and CV hospitalization even though was numerically better in Nebivolol than Bisoprolol but there was no significant difference between the two. With the advancement of beta-blockers, they are now again becoming an important option in the management of patients with hypertension and other cardiac diseases. It is important to understand the properties and advantages of various beta-blockers so that maximum advantage can be provided to the patients. Further, large-scale multicentric trials are needed to compare various beta-blockers.

\section{Additional Information}

\section{Disclosures}

Human subjects: Consent was obtained by all participants in this study. Nawabshah Medical College Board issued approval NWB/2016/06/13A. Animal subjects: All authors have confirmed that this study did not involve animal subjects or tissue. Conflicts of interest: In compliance with the ICMJE uniform disclosure form, all authors declare the following: Payment/services info: All authors have declared that no financial support was received from any organization for the submitted work. Financial relationships: All authors have declared that they have no financial relationships at present or within the previous three years with any organizations that might have an interest in the submitted work. Other relationships: All authors have declared that there are no other relationships or activities that could appear to have influenced the submitted work.

\section{References}

1. Lloyd-Jones D, Adams RJ, Brown TM, et al.: Heart Disease and Stroke Statistics-2010 update. A Report From the American Heart Association. Circulation. 2010, 121:1-170. 10.1161/CIRCULATIONAHA.109.878314

2. Taylor J.: 2013 ESH/ESC Guidelines for the management of arterial hypertension . Eur Heart J. 2013, 34:21082109.

3. Wiysonge CS, Bradley HA, Volmink J, et al.: Beta-blockers for hypertension . Cochrane Database Syst Rev. 2012, 11:002003. 10.1002/14651858.CD002003.pub4

4. Williams B, Mancia G, Spiering W, et al.: ESC/ESH guidelines for the management of arterial hypertension . Eur Heart J. 2018, 2018:3021-104. 10.1093/eurheartj/ehy339

5. Ponikowski P, Voors AA, Anker SD, et al.: 2016 ESC Guidelines for the diagnosis and treatment of acute and chronic heart failure: the Task Force for the diagnosis and treatment of acute and chronic heart failure of 
the. European Society of Cardiology (ESC). Developed. with the special contribution of the Heart Failure Association (HFA) of the ESC. Eur Heart J 2016, 37:2129-2200. 10.1093/eurheartj/ehw128

6. Fongemie J, Felix-Getzik E: A review of nebivolol pharmacology and clinical evidence . Drugs. 2015, 75:1349-1371. 10.1007/s40265-015-0435-5

7. Simova II, Todorova-Konstantinova RR, Denchev SV: Effects of nebivolol versus bisoprolol on endothelial function in hypertensive patients. Exp Clin Cardiol. 2009, 14:45-49.

8. Czuriga I, Riecansky I, Bodnar J, et al.: The NEBIS Investigators; NEBIS Investigators Group Comparison of the new cardioselective beta-blocker nebivolol with bisoprolol in hypertension: the Nebivolol, Bisoprolol Multicenter Study (NEBIS). Cardiovasc Drugs Ther. 2003, 17:257-63. 10.1023/a: 1026180325278

9. Contini M, Apostolo A, Cattadori G, et al.: Multiparametric comparison of CARvedilol, vs. NEbivolol, vs. BIsoprolol in moderate heart failure: the CARNEBI trial. Int J Cardiol. 2013, 168:2134-2140. 10.1016/j.ijcard.2013.01.277

10. Flather MD, Shibata MC, Coats AJ, et al.: Randomized trial to determine the effect of nebivolol on mortality and cardiovascular hospital admission in elderly patients with heart failure (SENIORS). Eur Heart J. 2005, 26:215-225. 10.1093/eurheartj/ehi115

11. The Cardiac Insufficiency Bisoprolol Study II (CIBIS-II): a randomised trial . Lancet. 1999, 353:9-13.

12. Veverka A, Salinas JL: Nebivolol in the treatment of chronic heart failure . Vasc Health Risk Manag. 2007, 3:647-654.

13. Bundkirchen A, Brixius K, Bölck B, Nguyen Q, Schwinger RH: Beta 1-adrenoceptor selectivity of nebivolol and bisoprolol. A comparison of [3H]CGP 12.177 and [125I]iodocyanopindolol binding studies. Eur J Pharmacol. 2003, 460:19-26. 10.1016/s0014-2999(02)02875-3

14. Tzemos N, Lim PO, MacDonald TM: Nebivolol reverses endothelial dysfunction in essential hypertension: a randomized, double-blind, crossover study. Circulation. 2001, 104:511-514. 10.1161/hc3001.094207

15. Falciani M, Rinaldii B, D’Agostino B, et al.: Effects of nebivolol on human platelet aggregation . J Cardiovasc Pharmacol. 2001, 38:922-29. 10.1097/00005344-200112000-00014

16. Brehm BR, Wolf SC, Bertsch D, et al.: Effects of nebivolol on proliferation and apoptosis of human coronary artery smooth muscle and endothelial cells. Cardiovasc Res. 2001:430-9. 10.1016/s0008-6363(00)00253-4 